\title{
Ensino Híbrido: aspectos teóricos e análise de duas experiências pedagógicas com Sala de Aula Invertida
}

Gilmara Teixeira Barcelos - IFFluminense - gilmarab@iff.edu.br Silvia Cristina Freitas Batista - IFFluminense - silviac@iff.edu.br

Resumo: De forma resumida, considera-se Ensino Híbrido como uma modalidade de ensino formal, na qual atividades presenciais e on-line são combinadas, de forma a contribuir para um ensino mais personalizado. No entanto, não há uma definição única para essa proposta, havendo variações inclusive em relação a que fatores podem ser combinados, de modo que a ação seja caracterizada como Ensino Híbrido. Nesse contexto, o presente trabalho tem por objetivo apresentar uma discussão sobre aspectos relacionados a essa modalidade de ensino. Tal discussão, que inclui considerações sobre a definição e sobre características dessa proposta, é respaldada por revisão bibliográfica e pela análise de duas experiências pedagógicas nas quais a Sala de Aula Invertida, uma forma de vivenciar o Ensino Híbrido, foi adotada. Dada a variedade de concepções e aspectos, considera-se fundamental que cada estudo relacionado ao tema Ensino Híbrido traga explicitamente a definição e a caracterização que o embasa.

Palavras-chave: Ensino Híbrido, tecnologias digitais, Sala de Aula Invertida.

\section{Blended Learning: theoretical aspects and analysis of two pedagogical experiences with Flipped Classroom}

\begin{abstract}
In short, Blended Learning is considered to be a formal teaching modality in which face-to-face and online activities are combined in order to contribute to a more personalized teaching. However, there is not just a single definition for this proposal, and there are variations even as to what factors can be combined, so that the action is characterized as Blended Learning. So, the present work aims to present a discussion about aspects related to this teaching modality. This discussion, which includes considerations on the definition and characteristics of this proposal, is supported by a literature review and the analysis of two pedagogical experiences in which the Flipped Classroom, a way of experiencing Blended Learning, was adopted. Given the variety of concepts and aspects, it is considered essential that each study related to the Hybrid Teaching theme explicitly brings the definition and characterization that support it.
\end{abstract}

Keywords: Blended Learning, Digital Technologies, Flipped Classroom.

\section{Introdução}

Os professores têm sido desafiados a atender às crescentes expectativas dos alunos conectados e também às demandas por experiências e resultados que contribuam para a melhoria do processo de ensino e aprendizagem com o apoio das tecnologias digitais (TD). A possibilidade de os alunos e professores estarem juntos on-line, a qualquer hora e em qualquer lugar, impactou ou deveria ter impactado a forma como as aulas presenciais ocorrem.

Neste contexto, propostas de Blended Learning (Ensino Híbrido, em português) têm estado em destaque no meio acadêmico. Diversas pesquisas (Garrison; Kanuka, 2004; Graham, 2006; Horn; Staker, 2015; Diep et al., 2017; Hrastinski, 2019) discutem o tema, porém algumas vezes há divergências entre as definições apresentadas, havendo enfoques mais abrangentes do que outros. Graham (2006) já discutia essa questão, 
atribuindo ao avanço contínuo das TD a não uniformidade nas definições usadas pelos pesquisadores do tema. Segundo Hrastinski (2019), a expressão Blended Learning tem englobado uma variedade de definições, sendo até mesmo adotada para descrever o uso de tecnologia na educação, de forma geral.

Neste artigo, a partir de estudos da área e de experiências pedagógicas realizadas, define-se Ensino Híbrido como uma modalidade de ensino formal na qual ocorrem atividades presenciais e on-line, de forma integrada e personalizada, com o objetivo de melhorar a construção de conhecimentos sobre o tema em estudo. Nessa proposta, o aluno deve ter alguma oportunidade de fazer escolhas (hora de estudar, tempo gasto no estudo, seleção e adaptação de materiais pesquisados) desenvolvendo assim sua autonomia no processo de ensino e aprendizagem com apoio das TD.

Como defendido por Grant e Basye (2014), as TD e as diversas abordagens pedagógicas que as utilizam podem contribuir para a personalização do ensino e para a autonomia e o engajamento dos estudantes, tornando-os mais ativos e mais responsáveis pela sua aprendizagem. Nessa perspectiva, considera-se que o uso de TD no Ensino Híbrido deve permitir o desenvolvimento da autonomia dos estudantes, indo muito além de ser apenas uma aula enriquecida com tecnologias.

Considerando o exposto, o objetivo deste artigo é apresentar uma discussão sobre aspectos relacionados ao Ensino Híbrido. Tal discussão, que inclui considerações sobre a definição e sobre características dessa modalidade de ensino, é respaldada por revisão bibliográfica e pela análise de duas experiências pedagógicas nas quais a Sala de Aula Invertida (SAI) foi adotada, das quais as autoras deste artigo participaram. A SAI é uma forma de vivenciar o Ensino Híbrido, na qual é proposta a inversão da lógica da sala de aula tradicional, ficando o estudo dos conteúdos como atividade extraclasse, com apoio de material on-line, e a discussão de ideias e a realização de tarefas diferenciadas sobre o tema como ações a serem realizadas de modo presencial.

Tendo em vista o objetivo descrito, este artigo encontra-se estruturado em outras três seções, além desta introdução. Na seção 2, promove-se uma caracterização da modalidade Ensino Híbrido. Na seção 3, são descritas e analisadas duas experiências nas quais a SAI foi adotada. Finalizando, na seção 4, são tecidas considerações finais sobre o tema abordado.

\section{Ensino Híbrido: aspectos gerais}

No processo de ensino e aprendizagem várias misturas (combinações) ocorrem, o que gera a discussão sobre o que é Ensino Híbrido. Afinal misturam-se vários aspectos, como estratégias, espaços, tempos, atividades, públicos, como defendido por Moran (2015). O referido autor destaca que a educação é uma área essencialmente híbrida, por diversos motivos, tais como: i) ocorre em uma sociedade imperfeita na qual há contradições entre políticas e modelos, ideais afirmados e práticas realizadas; ii) aprende-se por meio de processos formais, planejados institucional e intencionalmente, e também por processos informais; iii) alunos e professores são tanto consumidores quanto produtores de informação e conhecimento.

Essas combinações são naturais e importantes diante do perfil dos alunos e da forma como as informações estão disponíveis, o que decorre em parte do desenvolvimento das TD. Porém, neste artigo, considera-se que estas misturas não caracterizam a proposta do Ensino Híbrido. Como mencionado na introdução, neste artigo define-se Ensino Híbrido como uma modalidade de ensino formal na qual ocorrem atividades presenciais e on-line, de forma integrada e personalizada, tendo em vista contribuir para a construção de conhecimentos sobre o tema em estudo. Então, considera-se que a mistura essencial é entre atividades presenciais e on-line, mas é fundamental que todas as atividades sejam bem relacionadas entre si e que levem em 
consideração a individualidade dos estudantes, tendo como objetivo maior a aprendizagem.

No Quadro 1, são apresentadas as definições de Ensino Híbrido que fundamentaram a definição adotada neste artigo. Estas são, em essência, semelhantes entre si, diferindo em aspectos considerados como pouco significativos.

Quadro 1 - Definições de Ensino Híbrido

\begin{tabular}{|c|l|}
\hline $\begin{array}{c}\text { Obras } \\
\text { Consultadas }\end{array}$ & \multicolumn{1}{c|}{ Definições } \\
\hline $\begin{array}{c}\text { Garrison e } \\
\text { Kanuka } \\
\text { (2004) }\end{array}$ & $\begin{array}{l}\text { Integração efetiva de dois componentes principais (atividades presenciais e via Internet), } \\
\text { mas de tal forma que não seja uma simples adição de duas abordagens distintas. É } \\
\text { preciso ocorrer um afastamento desses dois componentes considerados isoladamente, } \\
\text { tendo em vista encontrar, por meio da combinação destes, uma reorganização } \\
\text { fundamental da dinâmica de ensino e aprendizagem, atendendo a várias necessidades } \\
\text { contextuais específicas. Nesse aspecto, não há dois projetos de Ensino Híbrido idênticos, } \\
\text { o que sinaliza a grande complexidade do tema. É importante que o aluno possa fazer } \\
\text { alguma escolha (organização do tempo de estudo, do trabalho individual ou em grupo, } \\
\text { fontes de estudos, entre outros). }\end{array}$ \\
\hline $\begin{array}{c}\text { Graham } \\
\text { (2006) }\end{array}$ & $\begin{array}{l}\text { Combinação de dois modelos de ensino e aprendizagem historicamente separados: } \\
\text { sistemas tradicionais de aprendizagem presenciais e sistemas de aprendizagem } \\
\text { distribuída (sistemas de ensino a distância, baseados no uso de tecnologias digitais de } \\
\text { informação e comunicação). No Ensino Híbrido, as tecnologias digitais têm um papel } \\
\text { fundamental, mas é preciso criar experiências efetivas que incorporem elementos dos } \\
\text { dois modelos (presencial e a distância mediado por tecnologias digitais). }\end{array}$ \\
\hline $\begin{array}{c}\text { Christensen et } \\
\text { al. (2013) }\end{array}$ & $\begin{array}{l}\text { Programa de educação formal no qual algumas atividades ocorrem por meio do ensino } \\
\text { on-line, permitindo algum grau de controle do estudante sobre o tempo, o local, o modo } \\
\text { e a forma e/ou ritmo do estudo, e outras atividades ocorrem em algum local físico fora } \\
\text { da residência do estudante, de forma supervisionada. }\end{array}$ \\
\hline
\end{tabular}

Fonte: Elaboração própria, a partir dos trabalhos mencionados.

Ressalta-se que, embora Ensino Híbrido possa parecer algo bem recente, a primeira definição apresentada no Quadro 1 é de um artigo que tem, aproximadamente, quinze anos. Em uma busca promovida na base Scopus ${ }^{1}$, realizada em doze de julho de 2019, usando "Blended Learning" como palavra-chave, pesquisando em títulos, resumos e palavras-chave, foi possível identificar um artigo de 2001 (Voci; Young, 2001) como sendo o mais antigo dessa base abordando o tema, de forma relacionada ao uso de Internet. A busca até retornou um artigo de 2000 (Cooney et al., 2000), mas a combinação discutida no mesmo não envolvia o uso de TD. Assim, é possível observar que o tema já tem sido discutido há algum tempo e, nesse contexto, alguns pesquisadores têm incorporado novos aspectos ao conceito, ampliando ou reduzindo seus limites.

Allen e Seaman (2010), por exemplo, destacam a importância de se estabelecer a porcentagem de conteúdos abordados presencialmente e on-line para definir se o processo pode ser caracterizado ou não como Ensino Híbrido. Para estes autores o ensino é considerado presencial quando a quantidade de conteúdo on-line está entre 0 (zero) e 29\%. Para ser Ensino Híbrido, consideram que uma proporção substancial do conteúdo deve ser entregue on-line, aproximadamente, 30\% a 79\%. Já no ensino a distância, mais de $80 \%$ do conteúdo deve ser disponibilizados on-line (Allen; Seaman, 2010). No entanto, considera-se que na prática não é simples utilizar tais porcentagens

\footnotetext{
1 Todas as buscas na base Scopus, descritas neste artigo, foram realizadas a partir do Portal de Periódicos
} da Capes, com acesso do Instituto Federal Fluminense. 
para caracterizar as modalidades de ensino, afinal o processo de ensino e aprendizagem não é estático, vários são os aspectos que devem ser considerados. Além disso, discorda-se, no presente estudo, que o simples uso de tecnologias on-line caracterize Ensino Híbrido, ou seja, o uso esporádico de um ambiente virtual de aprendizagem, ou de um site ou software não possibilita considerar que a modalidade é híbrida.

Em relação à forma de adoção de uma proposta híbrida por parte dos professores ou de instituições de ensino, Christensen et al.(2013), cuja definição de Ensino Híbrido encontra-se no Quadro 1, discutem duas possibilidades: por meio de propostas sustentadas ou disruptivas. As sustentadas não provocam mudanças bruscas nas atividades de sala de aula. Utilizam tecnologias digitais, com uma parte on-line, mas a sala de aula tradicional é mantida. Essa é uma possibilidade que favorece a adoção por parte dos professores, uma vez que não exige mudanças muito bruscas. Já nas disruptivas, as mudanças são radicais, rompendo com a sala de aula tradicional, o que leva a ser mais difícil de ser implementada (Christensen et al. 2013).

Considerando as ações institucionais, Graham et al. (2013) afirmam que é possível identificar diferentes estágios de adoção do Ensino Híbrido: i) consciência/exploração - é caracterizado por nenhuma estratégia institucional, mas com certa consciência da importância e apoio limitado ao professor, de forma individual; ii) adoção/implementação iniciante - caracterizada pela adoção institucional e pela experimentação de novas políticas e práticas para apoiar a implementação do Ensino Híbrido; iii) implementação madura/crescimento - caracterizado por estratégias, estrutura e suporte bem estabelecidos.

Garrison e Kanuka (2004) destacam fatores importantes em ações institucionais com Ensino Híbrido, no Ensino Superior: i) criação de política institucional clara; ii) incentivo à conscientização e comprometimento; iii) suporte para professores e estudantes; iv) criação de um fundo de inovação para fornecer apoio financeiro e incentivo para a realização das transformações necessárias aos cursos na modalidade híbrida; v) investimento em infraestrutura tecnológica confiável e acessível; vi) seleção estratégica de projetos bem-sucedidos que possam servir de exemplos; vii) desenvolvimento de suporte para design instrucional de cursos em formato híbrido; viii) avaliação sistemática da satisfação com o processo de ensino e aprendizagem, com a tecnologia e com a administração de cursos no formato híbrido; ix) criação de grupo de trabalho para abordar questões, desafios e oportunidades, bem como orientar novas ações.

No Quadro 2, apresentam-se outros fatores importantes para o sucesso de práticas de Ensino Híbrido. Estes foram determinados por meio de uma revisão de literatura promovida em trabalhos identificados em uma pesquisa feita na base Scopus, no dia 20 de julho de 2019. Na referida pesquisa, utilizou-se a string "Blended Learning" AND "review", buscando somente nos títulos e considerando apenas trabalhos publicados em 2019. Dessa forma, foram identificados cinco artigos, todos discutindo revisões da literatura relacionadas ao tema. No entanto, dois desses trabalhos foram excluídos, um por ser muito específico da área de saúde e outro por falta de acesso gratuito ao mesmo. O Quadro 2 apresenta os fatores identificados nos três artigos selecionados. 
Quadro 2 - Ensino Híbrido: fatores importantes para o sucesso

\begin{tabular}{|c|c|}
\hline $\begin{array}{c}\text { Obras Consultadas/ Objetivo } \\
\text { Geral }\end{array}$ & Fatores \\
\hline $\begin{array}{l}\text { Putri et al. (2019) } \\
\text { O objetivo da pesquisa foi } \\
\text { investigar, a partir de revisão } \\
\text { sistemática da literatura, } \\
\text { promovida em } 24 \text { journals, os } \\
\text { principais fatores de sucesso na } \\
\text { implementação do Ensino } \\
\text { Híbrido para o ensino de Inglês, } \\
\text { no contexto do Ensino Superior. }\end{array}$ & $\begin{array}{l}\text { Foram identificados } 11 \text { fatores críticos para a adoção do Ensino } \\
\text { Híbrido no contexto considerado, entende-se, no entanto, que estes } \\
\text { não são específicos para o ensino de Inglês, podendo ser } \\
\text { considerados de forma mais ampla: } \\
\text { i) design do curso a ser implementado; } \\
\text { ii) modelo instrucional; } \\
\text { iii) método de ensino e aprendizagem; } \\
\text { iv) ferramentas para ensino on-line; } \\
\text { v) resultados ou objetivos de aprendizagem; } \\
\text { vi) engajamento e envolvimento dos estudantes em sua } \\
\text { aprendizagem; } \\
\text { vii) ambiente virtual de aprendizagem; } \\
\text { viii) apoio institucional; } \\
\text { ix) materiais de ensino-aprendizagem; } \\
\text { x) estilo de aprendizagem dos alunos; } \\
\text { xi) fatores demográficos (características da população, tais como } \\
\text { idade, nível educacional, nível social, entre outros). }\end{array}$ \\
\hline $\begin{array}{l}\text { Listiana e Jaharadak (2019) } \\
\text { A pesquisa buscou promover uma } \\
\text { revisão da literatura, nas bases } \\
\text { Elsevier Science Direct, } \\
\text { IEEExplore e Google Scholar, } \\
\text { sobre características do Ensino } \\
\text { Híbrido e investigar problemas e } \\
\text { desafios relacionados a essa } \\
\text { proposta. }\end{array}$ & $\begin{array}{l}\text { A pesquisa identificou três questões fundamentais a serem } \\
\text { consideradas em ações com Ensino Híbrido: } \\
\text { i) conteúdo abordado: o da parte on-line não deve ser uma } \\
\text { reprodução do que é tradicionalmente utilizado no contexto } \\
\text { presencial e deve ser centrado no aluno, buscando facilitar a } \\
\text { interação entre estudante-estudante e estudante-professor; } \\
\text { ii) interações: as presenciais devem contribuir para aumentar a } \\
\text { presença social on-line e a motivação para discussões em grupo, } \\
\text { em fóruns ou chats; as interações on-line devem fazer uso de } \\
\text { recursos síncronos e assíncronos, tendo em vista contribuir para } \\
\text { o engajamento e a motivação alunos; } \\
\text { iii) professores iniciantes: necessitam de treinamento para que } \\
\text { possam entender o processo e, assim, contribuir para a } \\
\text { aprendizagem dos estudantes. }\end{array}$ \\
\hline $\begin{array}{l}\text { Philipsen et al. (2019) } \\
\text { O estudo promoveu uma revisão } \\
\text { sistemática meta-agregativa de } \\
\text { literatura (correspondente à } \\
\text { revisão sistemática da literatura, } \\
\text { mas para síntese de evidências } \\
\text { qualitativas), na base Web of } \\
\text { Science, tendo por objetivo } \\
\text { identificar componentes } \\
\text { importantes das estratégias de } \\
\text { desenvolvimento profissional de } \\
\text { professores para o Ensino On-line } \\
\text { e Ensino Híbrido. }\end{array}$ & $\begin{array}{l}\text { Foram identificados seis fatores importantes para a realização de } \\
\text { estratégias para o desenvolvimento profissional de professores para } \\
\text { o Ensino On-line e Ensino Hibrido: } \\
\text { i) apoio aos professores participantes, em todo o processo, e } \\
\text { feedback constante. O tempo de duração da estratégia de } \\
\text { formação proposta deve ser adequado aos objetivos pretendidos; } \\
\text { ii) atenção a aspectos institucionais, uma vez que a formação } \\
\text { envolve indivíduos, mas depende de fatores institucionais, tais } \\
\text { como características específicas, planejamento da instituição, } \\
\text { possível existência de programas paralelos e fatores financeiros; } \\
\text { iii) reflexão dos próprios professores sobre questões relacionadas à } \\
\text { identidade profissional, concepçães educacionais e papéis que } \\
\text { devem desempenhar no processo; } \\
\text { iv) entendimento, por parte dos professores, da relevância da } \\
\text { formação proposta e compreensão clara dos objetivos a serem } \\
\text { alcançados; } \\
\text { v) adoção de estratégias adequadas que possam contribuir para que } \\
\text { os professores alcancem seus objetivos, diminuindo a ansiedade } \\
\text { e a apreensão diante de mudanças e aumentando a confiança e } \\
\text { motivação; } \\
\text { vi) avaliação da proposta de formação adotada, tendo em vista } \\
\text { sempre melhorá-la, e realização de açães para disseminação de } \\
\text { conhecimentos, incentivando que cada professor possa contribuir } \\
\text { com a formação de outros colegas. }\end{array}$ \\
\hline
\end{tabular}

Fonte: Elaboração própria, a partir dos trabalhos mencionados. 
Observa-se, por meio do Quadro 2 e também da discussão que o antecede, que são diversos os fatores a serem considerados na implementação de ações com Ensino Híbrido. De forma resumida, é possível destacar dois aspectos: o papel do professor e o comprometimento institucional. Como defendido por Bacich, Tanzi Neto e Trevisani, (2015), a atuação do professor é um aspecto essencial, uma vez que este é o responsável por incentivar o trabalho colaborativo, com foco no compartilhamento de experiência e na autonomia do aluno. Mas, certamente, a atuação do professor está relacionada ao apoio e comprometimento institucional. Como afirma Moran (2015), a organização do currículo, das estratégias metodológicas, do tempo e dos espaços precisa ser repensada no Ensino Híbrido e isso é algo complexo, pois depende de um plano estratégico a ser estabelecido pelas instituições. No entanto, inicialmente, as instituições podem agir de forma mais pontual, apoiando professores, gestores, alunos e pais em ações menores, promovendo mudanças incrementais aos poucos (Moran, 2015).

Considerando o contexto educacional do Brasil, é possível, ainda, listar alguns desafios para a implementação do Ensino Híbrido: i) acesso à Internet de qualidade na escola e fora dela; ii) o hábito dos alunos de receberem as informações de forma expositiva desde os anos iniciais da educação formal; iii) a falta de tempo dos professores, decorrente de suas diversas atribuições, aspecto que entra em conflito com o tempo necessário para o planejamento das atividades e elaboração de materiais; iv) turmas com muitos alunos, o que dificulta a personalização do ensino. Nesse sentido, propostas de Ensino Híbrido em formatos que não provoquem mudanças bruscas no cenário educacional tradicional tendem a ter melhor receptividade.

Christensen et al. (2013) propõem categorias para o Ensino Híbrido e, como já mencionado nesta seção, discutem a questão de algumas serem opções sustentadas e outras disruptivas. Segundo os referidos autores, o Ensino Híbrido pode ser experimentado em quatro categorias: Flex, A La Carte, Virtual Enriquecido e de Rotação. Essa última categoria se divide em subcategorias: Rotação por Estações, Laboratório Rotacional, Sala de Aula Invertida e Rotação Individual. Destas, apenas o Laboratório Rotacional, a SAI e a Rotação por Estações são inovações sustentadas, as demais são disruptivas. Na subseção seguinte, caracteriza-se a categoria SAI, pois as experiências descritas na seção seguinte foram promovidas nessa categoria.

\subsection{Sala de Aula Invertida (SAI)}

A SAI ou Flipped Classroom, em inglês, propõe a inversão da prática tradicional da sala de aula (Bergmann; Sams, 2012), isto é, o conteúdo é estudado pelos alunos antes da aula presencial. O estudo é feito em casa ou em outro local fora da escola por meio de conteúdos e lições on-line (Christensen et al., 2013). Essa abordagem contempla a utilização de tecnologias digitais (TD), de modo a contribuir para a construção do conhecimento, por meio de videoaulas, jogos, arquivos de áudio, applets, entre outras ferramentas digitais. Com auxílio desses recursos, o professor pode otimizar o tempo em sala de aula e utilizá-lo em atividades interativas, aprofundamento e discussões sobre o tema abordado (Barseghian, 2011). Cabe ressaltar que essas atividades de sala de aula podem ou não envolver o uso de TD, o fundamental é levar o aluno a refletir criticamente sobre o que foi estudado previamente.

Schmitz (2016) cita algumas tecnologias que podem ser utilizadas no contexto da SAI, tais como: vídeos e videoaulas; podcast, vodcast e screencast; smartphones, tablets; questionários eletrônicos do tipo quiz; fóruns, wikis; cursos e objetos de aprendizagem; repositórios online, como Coursera, Khan Academy; plataformas de ensino como o AVA Moodle, dentre outras.

Segundo Valente (2014), a SAI, com apoio das TD, pode possibilitar que o aluno seja um participante ativo e não simplesmente um receptor de informações, 
propiciando-o, por exemplo, o desenvolvimento de sua capacidade intelectual em resolver problemas ou desenvolver projetos. Para que isso ocorra, segundo Masetto (2006), o papel do professor como facilitador na mediação pedagógica é primordial, uma vez que ele se apresenta como elo entre o aprendiz e sua aprendizagem colaborando para que o aluno consiga alcançar os objetivos.

A SAI, segundo Sota (2016), apresenta alguns benefícios, tais como: i) favorecer a aprendizagem personalizada, à medida que otimiza o tempo de aula para construir relacionamentos e focar nas competências metacognitiva, social e emocional; ii) dar ao professor e ao aluno um feedback imediato do trabalho realizado; iii) criar mais oportunidades de colaboração e interação entre os alunos, permitindo aos que compreenderam o conteúdo ajudar àqueles que apresentam dificuldade; iv) desenvolver no aluno o senso de responsabilidade pelo seu aprendizado.

Como qualquer metodologia de ensino, a SAI também apresenta algumas dificuldades: i) trabalho gasto na elaboração de materiais; ii) domínio tecnológico dos professores para produção e seleção de vídeos e materiais; ii) acesso à Internet; iii) aceitação da metodologia por parte dos alunos e pais (SATO, 2016).

Como a SAI é uma subcategoria da modalidade Ensino Híbrido, é natural que os pontos positivos e dificuldades sejam semelhantes aos discutidos anteriormente para a modalidade de maneira geral. No cenário educacional nacional atual, a aceitação da proposta da SAI, que requer estudos prévios, fora do ambiente escolar, ainda é uma dificuldade comum de ocorrer no início de ações com essa metodologia, como é possível observar no Quadro 3. Os trabalhos apresentados nesse quadro foram identificados em pesquisa realizada em 22 de julho de 2019, no Google Acadêmico, considerando a expressão exata "Sala de Aula Invertida" no título, com presença de pelo menos uma das expressões "Ensino Fundamental”, "Ensino Médio" ou "Ensino Superior”, em publicações a partir de 2018. Essa busca retornou exatamente os quatro descritos no Quadro 3, que descrevem pesquisas promovidas no Brasil.

Quadro 3 - Trabalhos relacionados à metodologia SAI

\begin{tabular}{|c|c|c|c|}
\hline $\begin{array}{c}\text { Titulo e } \\
\text { Autor/Tipo }\end{array}$ & $\begin{array}{c}\text { Objetivo e } \\
\text { Público-Alvo da } \\
\text { pesquisa }\end{array}$ & Recursos & Resultados \\
\hline $\begin{array}{c}\text { Sala de Aula } \\
\text { invertida e fatores } \\
\text { intervenientes da } \\
\text { aprendizagem: } \\
\text { experiência em uma } \\
\text { instituição federal de } \\
\text { ensino superior com } \\
\text { uma turma de alunos } \\
\text { de graduação } \\
\text { Nóbrega et al. } \\
\text { (2018)/Artigo }\end{array}$ & $\begin{array}{l}\text { Investigar os fatores } \\
\text { intervenientes da } \\
\text { aprendizagem a partir } \\
\text { da aplicação da sala de } \\
\text { aula invertida em uma } \\
\text { turma de graduação de } \\
\text { uma Instituição Federal } \\
\text { de Ensino Superior } \\
\text { Público-alvo: alunos de } \\
\text { uma turma de Ensino } \\
\text { Superior de uma } \\
\text { Instituição Federal }\end{array}$ & $\begin{array}{c}\text { Ambiente } \\
\text { virtual da } \\
\text { instituição, } \\
\text { sites } \\
\text { gerenciadores } \\
\text { de referências, } \\
\text { textos, imagens, } \\
\text { músicas e quiz }\end{array}$ & $\begin{array}{l}\text { Melhor participação e interesse } \\
\text { dos alunos no aprendizado } \\
\text { individual e em grupo, } \\
\text { propiciando o protagonismo } \\
\text { discente. } \\
\text { Embora todos os participantes } \\
\text { tenham avaliado, em um } \\
\text { questionário, o material didático } \\
\text { proposto como excelente, } \\
\text { alguns reconheceram, durante } \\
\text { diálogos na sala de aula física, } \\
\text { que não tinham lido os materiais } \\
\text { e outros relataram ter utilizado } \\
\text { os recursos mais lúdicos, como } \\
\text { os slides animados, com uma } \\
\text { linguagem mais próxima do } \\
\text { público jovem. }\end{array}$ \\
\hline
\end{tabular}




\begin{tabular}{|c|c|c|c|}
\hline $\begin{array}{l}\text { Metodologias Ativas } \\
\text { no Ensino Superior: } \\
\text { uma proposta de } \\
\text { oficina sobre } \\
\text { aprendizagem por } \\
\text { pares; sala de aula } \\
\text { invertida; } \\
\text { aprendizagem } \\
\text { baseada em problema } \\
\text { e rotação por estações } \\
\text { de trabalho } \\
\text { Silva A. et al. } \\
\text { (2018)/Artigo }\end{array}$ & $\begin{array}{l}\text { Apresentar quatro } \\
\text { metodologias ativas e } \\
\text { analisar e discutir os } \\
\text { resultados visando } \\
\text { contribuir com a } \\
\text { ampliação de espaços } \\
\text { de formação que } \\
\text { propicie a apropriação } \\
\text { de conhecimentos } \\
\text { sobre novas } \\
\text { metodologias de } \\
\text { ensino, conciliando } \\
\text { teoria e prática. } \\
\text { Público-alvo: } \\
\text { professores do Ensino } \\
\text { Superior de uma } \\
\text { Universidade Federal } \\
\end{array}$ & $\begin{array}{c}\text { Ambiente } \\
\text { virtual Moodle } \\
\text { vídeos, textos e } \\
\text { enquetes }\end{array}$ & $\begin{array}{l}\text { Os resultados sinalizaram boa } \\
\text { aceitação em relação às } \\
\text { metodologias propostas e } \\
\text { aumento no conhecimento sobre } \\
\text { as mesmas. Como alguns } \\
\text { participantes esperavam um } \\
\text { aprofundamento nas } \\
\text { metodologias, foi identificada a } \\
\text { necessidade de, posteriormente, } \\
\text { complementar a oficina com } \\
\text { outros módulos mais } \\
\text { específicos. } \\
\text { A participação prévia, relativa } \\
\text { ao estudo dos conteúdos e ao } \\
\text { preenchimento de uma enquete } \\
\text { inicial, no entanto, foi uma } \\
\text { dificuldade evidenciada. }\end{array}$ \\
\hline $\begin{array}{c}\text { Aplicação de sala de } \\
\text { aula invertida para o } \\
\text { aprendizado de língua } \\
\text { portuguesa no Ensino } \\
\text { Médio } \\
\text { de escola pública } \\
\text { Silva M. et al. } \\
\text { (2018)/Artigo }\end{array}$ & $\begin{array}{c}\text { Identificar } \\
\text { potencialidades e } \\
\text { fragilidades na adesão } \\
\text { de metodologias ativas } \\
\text { mediadas pelas } \\
\text { Tecnologias Digitais } \\
\text { de Informação e } \\
\text { Comunicação na } \\
\text { perspectiva do modelo } \\
\text { híbrido Sala de Aula } \\
\text { Invertida, no ensino } \\
\text { público } \\
\text { Público-alvo da } \\
\text { pesquisa: alunos da } 2^{\text {a }} \\
\text { série do Ensino Médio } \\
\text { de uma instituição } \\
\text { pública estadual de São } \\
\text { Paulo }\end{array}$ & $\begin{array}{l}\text { Google Form, } \\
\text { grupo de } \\
\text { WhatsApp, } \\
\text { vídeos, textos e } \\
\text { charges }\end{array}$ & $\begin{array}{l}\text { A pesquisa sinalizou que o } \\
\text { Google Form pode ser utilizado } \\
\text { como ferramenta para auxiliar o } \\
\text { professor de língua portuguesa } \\
\text { no uso da SAI. Além disso, os } \\
\text { estudantes passam a ter maior } \\
\text { autonomia na realização das } \\
\text { atividades decidindo sobre o } \\
\text { tempo, local e o ritmo para a sua } \\
\text { realização, sem depender da } \\
\text { presença física do professor. A } \\
\text { experiência com a SAI foi } \\
\text { considerada positiva, embora as } \\
\text { primeiras atividades não tenham } \\
\text { tido grande adesão, por falta de } \\
\text { hábito, o que foi superado } \\
\text { posteriormente. }\end{array}$ \\
\hline $\begin{array}{c}\text { Uma análise da } \\
\text { aplicação das } \\
\text { metodologias sala de } \\
\text { aula invertida e } \\
\text { aprendizagem } \\
\text { baseada em projetos } \\
\text { em turmas do Ensino } \\
\text { Médio integrado } \\
\text { Santos (2019)/ } \\
\text { Dissertação }\end{array}$ & $\begin{array}{l}\text { Identificar, analisar e } \\
\text { avaliar os fatores } \\
\text { positivos e negativos } \\
\text { da aplicação das } \\
\text { metodologias sala de } \\
\text { aula invertida e } \\
\text { aprendizagem baseada } \\
\text { em projetos na turma } \\
\text { do } 2^{\text {a }} \text { série do Ensino } \\
\text { Médio técnico } \\
\text { integrado em Guia de } \\
\text { turismo. } \\
\text { Público-alvo da } \\
\text { pesquisa: alunos do } \\
\text { Ensino Médio de um } \\
\text { Instituto Federal de } \\
\text { Educação }\end{array}$ & $\begin{array}{l}\text { Vídeos, sites e } \\
\text { textos }\end{array}$ & $\begin{array}{l}\text { Foi identificado que as duas } \\
\text { metodologias possibilitaram: i) } \\
\text { maior interação entre professor } \\
\text { e aluno; ii) o uso, por parte do } \\
\text { professor, de uma variedade de } \\
\text { estratégias de ensino ao longo } \\
\text { do ano letivo; iii) maior } \\
\text { questionamento, por parte dos } \\
\text { alunos, nas aulas presenciais. } \\
\text { No entanto, também foram } \\
\text { observadas as seguintes } \\
\text { dificuldades relativas à } \\
\text { aplicação da SAI: i) resistência } \\
\text { inicial de alunos e até mesmo de } \\
\text { professores, que faziam críticas } \\
\text { à proposta; ii) falta de Internet } \\
\text { em casa, problema apresentado } \\
\text { por 10\% dos alunos } \\
\text { participantes; iii) grande número } \\
\text { de alunos na turma, o que } \\
\text { dificultou o feedback do } \\
\text { professor em tempo hábil. }\end{array}$ \\
\hline
\end{tabular}

Fonte: Elaboração própria, a partir dos trabalhos mencionados. 
Nos dois primeiros trabalhos do Quadro 3, não são descritos detalhes das atividades presenciais, o que não possibilitou a análise se estas incentivavam um papel ativo do aluno em seu processo de aprendizagem, de forma a desenvolver a autonomia. Já nos dois últimos, há relato de atividades presenciais nesse sentido: no terceiro trabalho, a professora iniciou a aula presencial discutindo a temática abordada no formulário on-line, propôs análises de materiais impressos mais complexos e organizou as salas em pequenos grupos de trabalho para a confecção de um jornal mural contendo todos os conteúdos estudados, tais como a elaboração de notícia, entrevista, charge, artigo de opinião e classificados. No quarto trabalho, em sala de aula, ocorreu debate.

Nos quatros estudos, foi possível identificar alguma dificuldade em relação à inversão proposta na SAI, tanto nos que relataram, de forma mais específica, dificuldades associadas à necessidade de estudar previamente os conteúdos, quanto nos que, de maneira mais ampla, descreveram dificuldades de aceitação da proposta metodológica. Toda mudança requer um tempo de adaptação e, nesse contexto, é fundamental que todos os envolvidos em ações educacionais inovadoras compreendam os objetivos pedagógicos pretendidos, evitando que estas pareçam sem sentido para alguns.

\section{Compartilhando Experiências}

Experiências com a SAI têm sido realizadas em contextos relacionados às atividades do projeto de pesquisa, à Licenciatura em Matemática, à Pós-Graduação Lato Sensu Docência no Século XXI: educação e tecnologias e ao Mestrado Profissional em Ensino e suas Tecnologias no Instituto Federal de Educação, Ciências e Tecnologia Fluminense. Nesta seção, são descritas e analisadas as duas experiências decorrentes da pós Lato Sensu, que foram orientadas pelas autoras deste artigo. Encerrando esta seção, promove-se uma caracterização das duas experiências, com base na discussão teórica promovida na seção 2 , tendo em vista destacar aspectos que possibilitam considerá-las ações de Ensino Híbrido, segundo a concepção adotada neste artigo.

\subsection{Sala de Aula Invertida no estudo de Língua Inglesa: uma experiência usando o ambiente Schoology}

Essa pesquisa foi realizada por Rangel (2018), em 2017, no âmbito da Pósgraduação Docência no Século XXI: educação e tecnologias. O objetivo geral foi analisar uma experiência com a SAI no estudo de Língua Inglesa, promovida com estudantes do último módulo do Curso Técnico em Eletromecânica de uma Instituição Federal de Educação. Na referida experiência, foi utilizado o ambiente virtual de aprendizagem Schoology, em sua versão gratuita.

O Schoology é um ambiente baseado em Computação em Nuvem, que dispõe de ferramentas que permitem que um professor compartilhe recursos e crie experiências educacionais, de maneira diferenciada (Schlager, 2016). Dentre suas várias funções, encontram-se: participação em grupos; criação/gerenciamento de cursos; compartilhamento de documentos (aluno e professor) e criação de fóruns de discussão (Schoology, 2017). O Schoology possui características muito semelhantes a uma rede social e sua versão gratuita é bastante funcional, possibilitando o uso de diversos recursos importantes para o contexto educacional.

Nessa pesquisa, o tema abordado com os alunos foi Passado Simples dos Verbos Regulares e, para tanto, foram organizados dois momentos on-line e dois presenciais, com as seguintes atividades:

- $1^{\circ}$ momento on-line - i) assistir a dois vídeos com links para o Youtube sobre o tema proposto e fazer anotações sobre o conteúdo abordado para discussão na 
aula presencial, em caso de dúvidas; ii) consultar uma apresentação (arquivo em pdf produzido pelo próprio professor) que enfatizava pontos relevantes dos dois vídeos; iii) realizar um quiz, no Schoology;

- $1^{0}$ momento presencial - em grupo: i) ler um material impresso relativo ao tema e resolver os exercícios propostos no mesmo; ii) resolver uma tarefa escrita, distribuída para cada grupo e, em seguida, comparar e discutir com outro grupo o resultado obtido; iii) refazer questões do quiz ( $1^{\circ}$ momento on-line), em caso de necessidade; iv) escolher respostas corretas em um jogo digital;

- $\quad 2^{\circ}$ momento on-line - i) assistir a um vídeo com link para o Youtube sobre o tema e responder a perguntas; ii) assistir a três vídeos sobre o tema e fazer anotações para facilitar o estudo; iii) ouvir e repetir um áudio disponibilizado no ambiente contendo verbos regulares e, em seguida, gravar e postar no Schoology um áudio ou vídeo, utilizando algum dispositivo móvel, dizendo três frases com os referidos verbos;

- $\quad 2^{\circ}$ momento presencial - em grupo: i) discutir e explicar entre eles as regras e pronúncia das terminações dos verbos regulares vistos nos vídeos do segundo momento on-line; ii) resolver uma tarefa escrita, entregue para cada grupo; iii) fazer dois exercícios, um para colocar em ordem cronológica dez expressões que indicavam tempo passado e outro no qual os membros do grupo deveriam produzir oralmente frases utilizando as referidas expressões.

A análise promovida foi qualitativa, baseada na avaliação dos alunos participantes. Os dados foram coletados por meio de questionário, observação e registro de dados do Schoology.

Participaram da pesquisa os seis alunos da turma considerada, nomeados E1, E2, E3, E4, E5 e E6. Nos dois momentos presenciais, foi possível observar que os alunos realizaram, colaborativamente, as atividades em grupo, alcançando o objetivo do estudo do tema proposto. Durante a mediação pedagógica, observou-se que alguns alunos consultaram anotações no caderno, relacionadas aos materiais disponibilizados para os momentos on-line.

Em relação à participação extraclasse, foi possível observar que nem todos realizaram as atividades propostas. Destaca-se que na última atividade on-line do segundo momento, na qual os alunos deveriam postar no Schoology um áudio ou um vídeo utilizando um smartphone ou tablet, apenas o aluno E5 conseguiu fazer essa tarefa, da forma solicitada. Os alunos E3, E4 e E6 a realizaram de forma escrita, justificando que o recurso disponível no Schoology para compartilhamento de áudio ou vídeo em dispositivos móveis não possibilitou a realização da atividade conforme solicitado. Os participantes E1 e E2 não fizeram a referida atividade.

De maneira geral, o Schoology teve suas características avaliadas de forma positiva pelos participantes, assim como a experimentação da proposta com a Sala de Aula Invertida. Foi possível perceber, como pontos favoráveis, que a SAI proporcionou uma participação mais ativa dos alunos nas atividades e maior colaboração entre eles, assim como uma otimização do tempo em sala de aula para trabalhar o conteúdo em estudo, de forma mais eficaz. Algumas dificuldades também foram observadas, tais como: i) baixa motivação de alguns alunos para se prepararem para as aulas presenciais, estudando os materiais disponibilizados e respondendo às atividades no Schoology; ii) resistência em relação ao trabalho colaborativo, manifestada por alguns alunos logo no início do primeiro momento presencial; iii) o tempo gasto na elaboração e seleção de materiais didáticos; iv) gerenciamento e planejamento de estratégias em sala de aula para dedicar o tempo a ajudar os alunos com dificuldade e a estimular os mais avançados. 


\subsection{Sala de Aula Invertida: uso do Google Sala de Aula no estudo de História}

Esta pesquisa foi realizada por uma ex-aluna da Pós-Graduação Lato Sensu mencionada e sua orientadora (Silva; Barcelos, 2017). O objetivo geral foi analisar uma experiência realizada com alunos de uma turma do Ensino Médio Regular, no município de São João da Barra, RJ, utilizando a SAI e o ambiente virtual Google Sala de Aula no estudo da Expansão Marítima Europeia e a diversidade do continente africano. A pesquisa contou com a participação de 22 alunos.

O Google Sala de Aula é um serviço gratuito para professores e alunos, que utiliza armazenamento em nuvem do Google Drive. Neste ambiente é possível criar uma sala de aula virtual com links, atividades, textos, áudios, vídeos, entre outros recursos.

Os instrumentos de coleta de dados utilizados foram observação e as respostas às atividades propostas.

Durante três semanas, foram realizadas atividades presenciais e on-line, por meio do Google Sala de Aula:

- $1^{\mathrm{o}}$ momento presencial - i) apresentar a proposta metodológica com uso do Google Sala de aula, dos objetivos, do cronograma e das atividades a serem desempenhadas tanto na sala de aula virtual como na sala de aula presencial; ii) os alunos responderam a um questionário, contendo 10 perguntas fechadas sobre o perfil e sobre o uso de tecnologias digitais.

- $1^{\circ}$ momento on-line - i) assistir ao vídeo “As Grandes Navegações - História Ensino Médio - Telecurso aula 17” disponível no YouTube cujo link foi disponibilizado no "mural da turma", no Google Sala de Aula; ii) fazer um relatório sobre o vídeo; iii) postar no tópico da atividade;

- $2^{\circ}$ momento presencial - i) discutir sobre as principais características da Expansão Marítima Europeia, considerando o vídeo que foi assistido; ii) aprofundar o conteúdo por meio de exposição oral dialogada;

- $2^{\circ}$ momento on-line - em dupla: i) pesquisar em mídias digitais como revistas, jornais, bibliotecas, museus, dentre outros documentos, imagens de instrumentos náuticos da época da Expansão Marítima Europeia; ii) criar vídeo com as respectivas imagens; iii) postar o link do vídeo no tópico da atividade disponível no "mural da turma";

- $3^{\circ}$ momento presencial - i) apresentar, em forma de seminário, a pesquisa realizada no $2^{\circ}$ momento on-line; ii) debater o que foi apresentado no seminário.

- $3^{\circ}$ momento on-line - i) assistir ao vídeo "África-Brasil (Semente, Raiz e Tempo)” primeira e segunda parte, disponível no YouTube; ii) responder a um teste com 10 questões objetivas, criadas no formulário Google, cujo link foi disponibilizado no "mural da turma". As respostas do teste foram corrigidas automaticamente na planilha do Google drive.

- $4^{\circ}$ momento presencial - i) elaborar cartazes sobre escravidão e resistência, além da diversidade econômica, política, cultural e social do Continente africano atual; ii) exposição dos cartazes no mural da escola;

- $4^{\circ}$ momento on-line - i) responder a duas perguntas abertas, por meio da ferramenta "pergunta" do GooGle Sala de Aula, para investigar a percepção dos alunos sobre a metodologia Sala de Aula Invertida no estudo de História e a contribuição do Google Sala de Aula para a aprendizagem do conteúdo estudado. 
A análise dos dados sinalizou que a experimentação da SAI, com o uso do Google Sala de Aula, possibilitou a interação e o protagonismo dos alunos. Observou-se uma expressiva participação e colaboração na plataforma utilizada, autonomia e criatividade. Além disso, a proposta contribuiu para o processo de construção do conhecimento sobre o assunto abordado, de forma crítica, integrada e flexível, uma vez que os alunos pesquisaram, compartilharam e apresentaram, nos espaços utilizados, conteúdos de qualidade. Na fase inicial da experimentação, a dificuldade vivenciada foi a insegurança dos alunos no processo de construção do conhecimento ao utilizar o Google Sala de Aula, porém, por meio de feedbacks da professora, motivando e tirando dúvidas, os alunos foram progredindo.

\subsection{Caracterização das duas experiências como ações de Ensino Híbrido}

Considera-se que as duas experiências descritas apresentam as características de Ensino Híbrido, discutidas na seção 2.

Ambas ocorreram no ensino formal, com atividades presenciais e on-line, de forma integrada e personalizada, com o objetivo de melhorar a construção de conhecimentos sobre temas em estudo. A integração ocorreu uma vez que as atividades presenciais decorriam das que foram propostas on-line, realizando, a partir destas, discussões, retirada de dúvidas e aplicações diversas do estudo prévio realizado.

A personalização foi promovida por meio de estratégias em sala de aula para dar atenção a alunos com dificuldades, assim como para estimular os mais avançados. Em Rangel (2018), isso foi, inclusive, apontado como uma dificuldade relacionada à SAI, pois, além de planejar estratégias para dificuldades inerentes ao conteúdo, o professor precisa saber como lidar com os alunos que não promovem o estudo prévio como solicitado, de forma que estes consigam acompanhar as atividades, sem prejudicar os colegas que estudaram. Ressalta-se que, no questionário final do trabalho de Rangel (2018), um dos itens solicitava o grau de concordância diante de uma afirmação relativa à contribuição das atividades para uma aprendizagem mais pessoal, que respeitasse o ritmo do aluno. Nesse item, dos seis alunos, quatro assinalaram a opção Concordo Plenamente e os outros dois, a opção Concordo. Na pesquisa de Silva e Barcelos (2017), para esclarecimento de dúvidas e também para personalização, foram utilizadas mensagens síncronas e assíncronas. Além disso, feedbacks das atividades eram fornecidos por meio dos recursos "aviso” ou "pergunta”, disponíveis no "mural da turma”, criado no Google Sala de Aula.

Além disso, os alunos, nas duas experiências, tinham certo grau de autonomia em seu processo de aprendizagem, uma vez que no estudo prévio dos temas, tinham oportunidade de fazer algumas escolhas, como por exemplo, a hora de estudar e o tempo de estudo, por meio dos ambientes de aprendizagem utilizados.

Assim, considera-se que os aspectos estabelecidos na definição adotada neste artigo foram todos atendidos, o que permite classificar as experiências descritas como ações de Ensino Híbrido.

Além disso, em relação à classificação de Graham et al. (2013), citada na seção 2, quanto à adoção institucional do Ensino Híbrido, as duas experiências podem ser enquadradas no estágio consciência/exploração, pois foram iniciativas individuais.

Quanto aos fatores fundamentais em ações com o Ensino Híbrido especificados por Putri et al. (2019), conforme Quadro 2, nas duas experiência houve cuidado com: i) método de ensino e aprendizagem; ii) ferramentas para ensino on-line; iii) resultados ou objetivos de aprendizagem; iv) engajamento e envolvimento dos estudantes em sua aprendizagem; v) ambiente virtual de aprendizagem; vi) fatores demográficos, pois foram consideradas características do público-alvo. 
Os três aspectos listados por Listiana e Jaharadak (2019), apresentados no Quadro 2, também foram considerados no planejamento das duas experiência, pois houve atenção: i) ao conteúdo abordado em cada parte (presencial e on-line); ii) às interações promovidas; iii) ao professor: nas duas experiências, eram professores que buscaram formação em uma Pós-Graduação Lato Sensu e aplicaram a proposta da SAI em suas turmas.

Portanto, as experiências descritas atendem a diversos fatores discutidos na seção 2 deste artigo, o que reforça a classificação destas como ações de Ensino Híbrido.

\section{Considerações Finais}

A discussão proposta neste artigo foi decorrente de inquietações das autoras, ao observarem que a expressão Ensino Híbrido tem recebido diferentes interpretações, a ponto de ficar difícil distinguir uma aula enriquecida com tecnologias digitais de uma com Ensino Híbrido. Essa diversidade de entendimento ressalta a importância de o pesquisador especificar a definição adotada em seu estudo, deixando claro que aspectos estão sendo misturados e como a integração entre estes está sendo planejada.

Para maximizar os efeitos desta modalidade de ensino, é fundamental estabelecer, de forma clara, os objetivos a serem alcançados. A seleção e a adaptação/criação de TD para o Ensino Híbrido também devem ser fundamentadas nesses objetivos, para evitar trabalho ou custos desnecessários, sem impactos relevantes para o processo de ensino e aprendizagem.

Nessa modalidade de ensino, o aluno é o centro do processo, este se envolve ativamente tanto em atividades individuais quanto em grupo. Estas são realizadas dentro ou fora da escola, como forma de ampliar as possibilidades de construção de conhecimentos. Busca-se desenvolver no aluno autonomia, criatividade, pensamento crítico, atitudes para trabalhos em grupos, hábitos de estudo e a comunicação, aspectos importantes para a sociedade atual.

As experiências com a SAI, descritas neste artigo, sinalizam o quanto é importante possibilitar a vivência de ações distintas das tradicionais no processo de ensino e aprendizagem, em componentes curriculares diversos. Além disso, ao justificar tais experiências como coerentes com a proposta do Ensino Híbrido, buscou-se destacar que nem toda proposta que envolve ensino presencial e o uso de ambientes virtuais online é Ensino Híbrido.

\section{REFERÊNCIAS}

ALLEN, I. E.; SEAMAN, J. Class Differences: Online Education in the United States. 2010. Sloan Consortium. Disponível em: <https://files.eric.ed.gov/fulltext/ED529952.pdf > . Acesso em: 8 jul. 2019.

BACICH, L.; TANZI NETO, A.; TREVISANI, F. M. (Org.). Ensino Híbrido: personalização e tecnologia na educação. Porto Alegre: Penso, 2015.

BARSEGHIAN, T. Three trends that define the future of teaching and learning. 2011. Disponível em: <https://www.kqed.org/mindshift/7854/three-trends-that-define-thefuture-of-teaching-and-learning>. Acesso em: 24 de jul. 2019.

BERGMANN, Jonathan; SAMS, Aaron. Flip your classroom: reach every student in every class every day. [s.l.]: ISTE, 2012.

CHRISTENSEN, C. M.; HORN, M. B.; STAKER, H. Ensino Híbrido: uma Inovação Disruptiva?. 2013. Disponível em: <https://www.pucpr.br/wp- 
content/uploads/2017/10/ensino-hibrido_uma-inovacao-disruptiva.pdf>. Acesso em: 15 maio 2019.

COONEY, M. H.; GUPTON, P.; O’LAUGHLIN, M. Blurring the Lines of Play and Work to Create Blended Classroom Learning Experiences. Early Childhood Education Journal, v. 27, n. 3, p. 165-166, 2000. Disponível em: $<$ https://link.springer.com/article/10.1007/BF02694230>. Acesso em: 12 jul. 2019.

DIEP, A. N.; ZHU, C.; STRUYVEN, K.; BLIECK, Y. Who or what contributes to student satisfaction in different blended learning modalities? British Journal of Educational Technology, v.48, n. 2, p. 473-489, 2017. Disponível em: https://doi.org/10.1111/bjet.12431. Acesso em: 4 jul. 2019.

GARRISON, D. R.; KANUKA, H. Blended learning: Uncovering its transformative potential in higher education. Internet and Higher Education, n.7, p. 95-105, 2004. Disponível em: <https://doi.org/10.1016/j.iheduc.2004.02.001>. Acesso em: 4 jul. 2019.

GRAHAM, C. R. Blended learning systems: definition, current trends and future directions. In: Bonk, C. J; Graham C. R. (Ed.), The handbook of blended learning: Global perspectives, local Designs. San Francisco: Pfeiffer. p. 3-21, 2006.

GRAHAM, C. R.; WOODFIELD, W.; HARRISON, J. B. A framework for institutional adoption and implementation of blended learning in higher education. The Internet and Higher Education, v.18, p. 4-14, 2013

GRANT, P.; BASYE, D. Personalized learning: a guide for engaging students with technology. International Society for Technology in Education. e-book. 2014. Disponível em: $<$ https://www.intel.com/content/dam/www/public/us/en/documents/education/k12personalized-learning-guidebook.pdf> . Acesso em: 29 jul. 2019.

HORN, M.. B.; STAKER, H. Blended: usando a inovação disruptiva para aprimorar a educação. Tradução de Maria Cristina Gularte Monteiro. Porto Alegre: Penso, 2015.

HRASTINSKI, S. What do We Mean by Blended Learning? TechTrends: Linking Research and Practice to Improve Learning. v. 1 (on-line), p.1-6, 2019. Disponível em: <https://doi.org/10.1007/s11528-019-00375-5>. Acesso em: 3 jul. 2019.

LISTIANA, N.; JAHARADAK, A. A. Blended Learning as Instructional Media: Literature Review. Journal of Physics: Conference Series. IOP Publishing, v. 1167, n. 1, art. n. 012066, p. 1-10, 2019. Disponível em: $<$ https://iopscience.iop.org/article/10.1088/1742-6596/1167/1/012066/pdf>. Acesso em: 20 jul. 2019.

MASETTO, M. T. (Org.). Docência na universidade. 8. ed. Campinas: Papirus, 2006.

MORAN, J. M. Educação Híbrida: um conceito-chave para a educação, hoje. In: BACICH, L.; TANZI NETO, A.; TREVISANI, F. M. (Org.). Ensino Híbrido: personalização e tecnologia na educação. Porto Alegre: Penso, 2015. p.103-122.

NÓBREGA, P. P. da; DAVID, P. B.; SILVA, A. S. R. da. Sala de Aula Invertida e fatores intervenientes da aprendizagem: experiência em uma instituição federal de ensino superior com uma turma de alunos de graduação. Revista Paidéi@-Revista Científica de Educação a Distância, Santos - SP, v. 10, n. 18, p. 1 - 30, 2018.

PHILIPSEN, B.; TONDEUR, J.; PAREJA ROBLIN, N., VANSLAMBROUCK, S., ZHU, C. Improving teacher professional development for online and blended learning: 
74

A systematic meta-aggregative review. Educational Technology Research and Development, p. 1-30, 2019.

PUTRI, M. R.; LUKE, J. Y.; SELA, S. T. Critical success factor in blended learning for English training: a systematic literature review. Journal of Physics: Conference Series. IOP Publishing, v. 1175, n.1, art. n. 012251, p. 1-5, 2019. Disponível em: $<$ https://iopscience.iop.org/article/10.1088/1742-6596/1175/1/012251/pdf > . Acesso em 20 jul. 2019.

RANGEL, R. dos S.; BATISTA, S. C. F.; PEIXOTO, G. T. B. Sala de Aula Invertida: análise de uma experiência com o ambiente virtual Schoology. Revista Novas Tecnologias na Educação - RENOTE, v. 16, n.1, 2018. Disponível em: <https://seer.ufrgs.br/renote/article/view/86029/49392>. Acesso em: 20 jul. 2019.

SANTOS, C. L. dos. Uma análise da aplicação das metodologias sala de aula invertida e aprendizagem baseada em projetos em turmas do Ensino Médio Técnico Integrado. 112 p., 2019. Dissertação (Mestrado em Ensino de Ciências e Matemática)Universidade Federal de Alagoas (UFAL), Alagoas, 2019.

SCHLAGER, Derek. Schoology: The adoption of a Learning Management System. 2016. 58 f. Dissertação (Master of Arts in Education). St. Catherine University. Disponível em: $<$ http://sophia.stkate.edu/cgi/viewcontent.cgi?article=1185\&context=maed $>$. Acesso em: 10 jul. 2019.

SCHMITZ, E. X. da S.. Sala de Aula Invertida: uma Abordagem para Combinar Metodologias Ativas e Engajar Alunos no Processo de Ensino-Aprendizagem. 2016. 185 f. Dissertação (Tecnologias Educacionais em Rede). Universidade Federal de Santa Maria, Rio Grande do Sul. Disponível em: $<$ http://coral.ufsm.br/ppgter/images/Elieser_Xisto_da_Silva_Schmitz_Disserta\%C3\%A 7\%C3\%A3o_de_Mestrado.pdf>. Acesso em: 5 mar. 2018.

SCHOOLOGY. About Schoology. 2017. Disponível em: <https://www.schoology.com/about>. Acesso em: 14 jul. 2019.

SILVA, A. J. de C.; CRUZ, S. R. M.; SAHB, W. F. Metodologias ativas no Ensino Superior: uma proposta de oficina sobre aprendizagem por pares; sala de aula invertida; aprendizagem baseada em problema e rotação por estações de trabalho. In: SIMPÓSIO TECNOLOGIAS E EDUCAÇÃO A DISTÂNCIA NO ENSINO SUPERIOR, Minas Gerais. Anais ... Minas Gerais: UFMG, 2018. p. 1-12.

SILVA, F. C. dos S.; BARCELOS, G. T. Sala de Aula Invertida: uso do Google Classroom no estudo de História. In: CONGRESSO INTEGRADO DA TECNOLOGIA DA INFORMAÇÃO, 9., 2017, Campos dos Goytacazes. Anais ...Campos dos Goytacazes, IFF, 2017. p. 1-10.

SILVA, M. I. O. da; PESCE, L.; NETTO, A. V.. Aplicação de sala de aula invertida para o aprendizado de língua portuguesa no ensino médio de escola pública. Tecnologias, Sociedade e Conhecimento, Campinas- SP, v. 5, n. 1, p. 100-119, 2018.

SOTA, M. S. Flipped learning as a path to personalization. In: MURPHY, M.; REDDING, S.; TWYMAN, J. Handbook on personalized learning for states, districts, and schools. Philadelphia: Center on Innovations in Learning, 2016. cap. 2, p. 73-87.

VALENTE, J. A. Blended Learning e as mudanças no ensino superior: a proposta da sala de aula invertida. Educar em Revista. 2014. Disponível em: 
<http://www.scielo.br/pdf/er/nspe4/0101-4358-er-esp-04-00079.pdf>. Acesso em: 4 jul. 2019.

VOCI, E.; YOUNG, K. Blended learning working in a leadership development programme. Industrial and Commercial Training, v. 33, n.5, p. 157-161, 2001. Disponível em: <https://www.emerald.com/insight/content/doi/10.1108/00197850110398927/full/pdf>. Acesso em: 12 jul. 2019. 